\title{
EFEITO DE COBERTURAS À BASE DE FÉCULA DE MANDIOCA, LECITINA DE SOJA E CERA DE ABELHA NA PERDA DE MASSA E COR DE TOMATES DURANTE O AMADURECIMENTO
}

\author{
A. R. M. BARRETO ${ }^{1}$, R. H. L. LEITE $^{1}$, E. M. M. AROUCHA ${ }^{1}$, F. K. G. SANTOS ${ }^{1}$ \\ e T. A. OLIVEIRA ${ }^{1}$ \\ ${ }^{1}$ Universidade Federal Rural do Semiárido, Departamento de Agrotecnologia e Ciências Sociais \\ E-mail para contato: ricardoleite@ufersa.edu.br
}

\begin{abstract}
RESUMO - Foram estudadas coberturas a base de fécula de mandioca, glicerol, lecitina de soja e cera de abelha na evolução da cor e perda de massa de tomates. Formulações com diferentes concentrações de fécula, lecitina de soja e cera de abelha foram aplicadas sobre tomates em estágio de maturação verde. Utilizou-se um percentual de fécula de $3 \%$ em massa e $0,3 \%$ de glicerol para todas as formulações. Os percentuais de cera de abelha variaram entre 1,0 e $2,0 \%$; e os de lecitina entre 2,0 e 3,0 \%. Os tomates recobertos foram armazenados à temperatura ambiente $\left(27 \pm 2{ }^{\circ} \mathrm{C}\right)$, assim como o grupo de tomates sem cobertura usados como controle. Foram avaliados os parâmetros perda de massa, por gravimetria, e a cor, através de um colorímetro, durante sete dias. Os resultados mostraram que as coberturas a base de fécula de mandioca, lecitina de soja e cera de abelha não foram eficazes na redução da perda de massa dos tomates, porém, retardaram a evolução da cor dos frutos em comparação com o grupo controle.
\end{abstract}

\section{INTRODUÇÃO}

Devido à utilização excessiva de plásticos foi formado no planeta, durante as últimas décadas, um preocupante acúmulo de resíduos plásticos. A pesquisa atual busca a produção de plásticos biodegradáveis que podem ser aplicados sob a forma de filmes ou coberturas na conservação de alimentos, são facilmente obtidos de fontes renováveis e estendem a vida de prateleira de frutas e hortaliças causando efeito similar ao uso de uma atmosfera modificada na conservação destes alimentos (Fakhouri et al., 2007). Dentre os materiais usualmente pesquisados as proteínas e polissacarídeos apresentam-se como os biopolímeros mais promissores na produção de plásticos biodegradáveis uma vez que formam uma matriz coesa, além de serem abundantes e de origem renovável (Rigo, 2006).

Os polissacarídeos, em particular, são bons polímeros para a formação de filmes e coberturas para a conservação de alimentos. Sendo hidrofílicos os filmes formados tendo como base polissacarídeos tendem a oferecer eficientes barreiras para moléculas apolares como as do oxigênio e dióxido de carbono, no entanto, possuem fraca eficiência como barreira de umidade (Oliveira e Cereda, 2003). As propriedades do polissacarídeo utilizado podem ser determinantes nas propriedades do biofilme. $\mathrm{O}$ amido obtido a partir da mandioca além de possuir propriedades funcionais singulares 


\section{9 a 22 de outubro de 2014 \\ Florianópolis/SC}

é encontrado em abundância e relativamente a baixo custo (Larotonda, 2002). Os filmes obtidos a partir da fécula de mandioca são geralmente resistentes, transparentes e formam uma barreira aos gases envolvidos na respiração de frutas e hortaliças, promovendo uma melhor aparência e aumentando a vida de prateleira destes alimentos, tornando-os mais atrativos aos produtores e consumidores (Batista et al., 2007; EMBRAPA, 2010; Fakhouri et al., 2007).

Vários estudos realizados avaliam a utilização dos filmes de fécula de mandioca obtidos a partir de uma suspensão que possui apenas o polímero e o solvente, sendo este mais comumente a água. No entanto, na tentativa de aperfeiçoar as propriedades dos biofilmes podem ser elaborados filmes compostos adicionando à solução plastificantes e aditivos que contribuam positivamente nas propriedades mecânicas e de barreira ou ainda utilizando uma combinação de biopolímeros agregando as características positivas de cada um dos componentes utilizados (Fakhouri et al, 2007; Rojas-Graü et al., 2009).

Hidrocolóides como a fécula de mandioca são capazes de produzir melhores propriedades mecânicas nos filmes se comparados com os filmes formados a base de lipídios e substâncias hidrofóbicas, que podem, no entanto, conferir menor permeabilidade ao vapor de água e reduzir as perdas de massa de frutas e hortaliças durante o armazenamento (Fakhouri et al.,2007). Assim, pode ser vantajoso no uso de ambas as substâncias na formação de filmes biodegradáveis. Contudo, a incorporação de substâncias de naturezas distintas em uma matriz filmogênica não ocorre de maneira homogênea tornando necessário o uso de um emulsificante, como a lecitina de soja, nas melhores composições para que o filme se forme de maneira coesa.

O tomate é um dos vegetais mais importantes, tanto em valor econômico, com a segunda maior área de cultura (FAO, 2012); como também um dos mais consumidos no mundo seja em sua forma in natura ou processada em molhos, sucos, sopas ou desidratados (Quintana, 2013). Por ser o tomate um fruto climatério, seu processo de amadurecimento parte da elevação da atividade respiratória provocando uma série de transformações em suas características físicas e químicas como a perda da clorofila, síntese de carotenoides e amolecimento (Damasceno et al., 2003). É possível avaliar a evolução dos pigmentos e o estado de maturação do tomate por meio da cor. Para a classificação por meio desta propriedade são usadas cartas ou escalas de cor e equipamentos capazes de medir a cor refletida pelo tomate. Além disso, a cor tem papel fundamental na caracterização e avaliação da qualidade dos frutos, sendo este o principal parâmetro utilizado pelos consumidores no momento da escolha. Durante a maturação ocorrem mudanças na coloração em razão da degradação das clorofilas e a síntese dos carotenoides. Nos tomates maduros a coloração esperada é vermelha intensa e uniforme por dentro e por fora (Oliveira et al., 2012).

O presente trabalho busca encontrar um método viável na obtenção de filmes produzidos a partir da fécula de mandioca e cera de abelha, em diferentes proporções de matéria hidrofóbica e emulsificante, avaliando seu desempenho quando aplicados como cobertura na redução da perda de massa e variação de cor de tomates. 


\section{9 a 22 de outubro de 2014 \\ Florianópolis/SC}

\section{METODOLOGIA}

Misturas filmogênicas compostas foram produzidas utilizando fécula de mandioca (Tipo 1, Fecularia Lopes, Nova Londrina-PR) como polímero; água destilada, como solvente; glicerol (Barbosa Irmãos Ltda. Mossoró-RN), como plasticizante; cera de abelha (adquirida com apicultor local) como substância hidrofóbica; e atuando como emulsificante, a lecitina de soja (Farma Fórmula, Mossoró - RN). Os experimentos foram realizados no Laboratório de Tecnologia de Alimentos da Universidade Federal Rural do Semiárido - UFERSA.

Os tomates foram adquiridos no comércio local após seleção dos frutos em estágio de maturação verde sendo selecionados e agrupados por tamanho, cor e ausência de defeitos e injúrias. Os frutos foram então imersos em solução com 100 ppm de hipoclorito de sódio para sanitização por 15 minutos e em seguida secados à temperatura ambiente. No mesmo dia foram revestidos com a cobertura comestível.

Foram preparadas nove misturas filmogênicas, variando sua composição em cera de abelha e lecitina de soja, com a finalidade de avaliar os efeitos que a concentração destes componentes possui nas propriedades das coberturas. A fécula de mandioca foi utilizada em uma concentração de $3 \%$ e o glicerol foi aplicado em 10\% dessa massa. As formulações das misturas filmogênicas, numeradas de T1 a T9, estão apresentadas na Tabela 1.

Tabela 1 - Composição das misturas filmogênicas produzidas.

\begin{tabular}{lccccccccc}
\multicolumn{1}{c}{ Componente } & T1 & T2 & T3 & T4 & T5 & T6 & T7 & T8 & T9 \\
Fécula de Mandioca & $3,0 \mathrm{~g}$ & $3,0 \mathrm{~g}$ & $3,0 \mathrm{~g}$ & $3,0 \mathrm{~g}$ & $3,0 \mathrm{~g}$ & $3,0 \mathrm{~g}$ & $3,0 \mathrm{~g}$ & $3,0 \mathrm{~g}$ & $3,0 \mathrm{~g}$ \\
\hline Glicerol & $0,3 \mathrm{~g}$ & $0,3 \mathrm{~g}$ & $0,3 \mathrm{~g}$ & $0,3 \mathrm{~g}$ & $0,3 \mathrm{~g}$ & $0,3 \mathrm{~g}$ & $0,3 \mathrm{~g}$ & $0,3 \mathrm{~g}$ & $0,3 \mathrm{~g}$ \\
\hline Cera de Abelha & $1,0 \mathrm{~g}$ & $1,0 \mathrm{~g}$ & $1,0 \mathrm{~g}$ & $1,5 \mathrm{~g}$ & $1,5 \mathrm{~g}$ & $1,5 \mathrm{~g}$ & $2,0 \mathrm{~g}$ & $2,0 \mathrm{~g}$ & $2,0 \mathrm{~g}$ \\
\hline Lecitina de Soja & $2,0 \mathrm{~g}$ & $2,5 \mathrm{~g}$ & $3,0 \mathrm{~g}$ & $2,0 \mathrm{~g}$ & $2,5 \mathrm{~g}$ & $3,0 \mathrm{~g}$ & $2,0 \mathrm{~g}$ & $2,5 \mathrm{~g}$ & $3,0 \mathrm{~g}$ \\
\hline Água & $100 \mathrm{~g}$ & $100 \mathrm{~g}$ & $100 \mathrm{~g}$ & $100 \mathrm{~g}$ & $100 \mathrm{~g}$ & $100 \mathrm{~g}$ & $100 \mathrm{~g}$ & $100 \mathrm{~g}$ & $100 \mathrm{~g}$
\end{tabular}

Obtidas as misturas filmogênicas, estas são resfriadas para que as temperaturas das soluções aproximem-se da temperatura ambiente em que se encontram os tomates nos quais serão aplicadas. Feito isto os tomates são imersos na solução e para corrigir eventuais defeitos na cobertura, como acúmulo de material ou não fixação no produto, a solução é espalhada utilizando um pincel de cerdas macias. Como parâmetro de comparação dos efeitos da cobertura nos frutos, uma amostra de tomates sem a aplicação do material filmogênico, foi analisada em conjunto com os demais tomates tratados e tomada como grupo controle.

Os tomates ficaram expostos à temperatura ambiente de aproximadamente $29^{\circ} \mathrm{C}$ e à umidade relativa do ar de $60 \%$, sendo pesadas em balança analítica a cada 24 horas para avaliação da perda de 
massa durante 7 dias. As medidas dos parâmetros de cor $\left(a^{*}, b^{*}\right.$ e L) foram realizadas em triplicata na região equatorial dos frutos do tomate utilizando o colorímetro CR-10 da Konica Minolta Sensing Inc. durante sete dias em intervalos de 24 horas para posterior avaliação.

\section{RESULTADOS E DISCUSSÃO}

\subsection{Perda de Massa}

A Figura 1 mostra a evolução da perda de massa dos tomates submetidos às nove formulações diferentes de coberturas além do grupo controle.

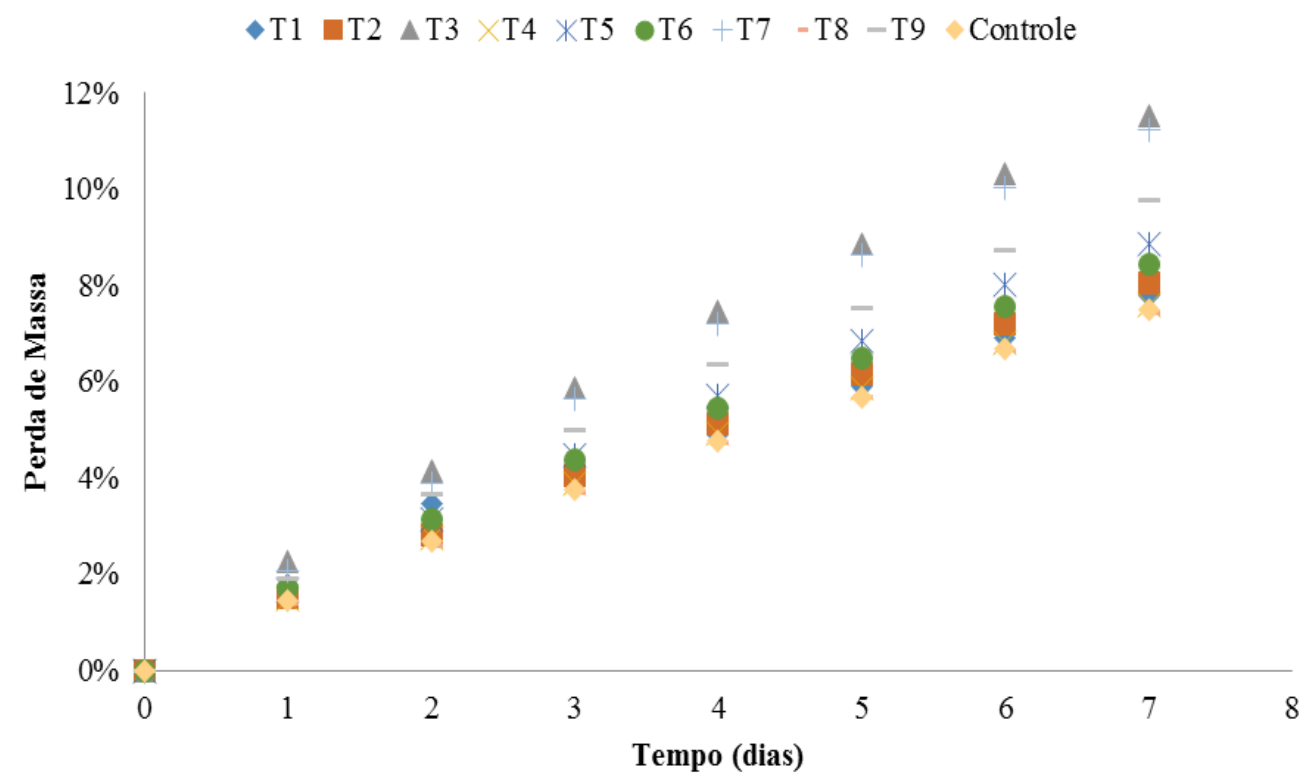

Figura 1 - Perda de massa dos tomates revestidos com as diferentes coberturas a base de fécula de mandioca/cera de abelha/lecitina de soja e glicerol (temperatura $=29^{\circ} \mathrm{C}$ e umidade $=60 \%$ )

Analisando a figura percebe-se que a grande maioria dos tratamentos obteve maior perda de massa quando comparados aos frutos que não tiveram aplicação de cobertura. Ao fim das observações os tomates tiveram perda de massa entre $7,43 \%$ e $11,54 \%$, sendo o menor valor para o tratamento T8 (7,43\%), com composições de $2 \%$ de cera de abelha e $2,5 \%$ de lecitina de soja. No entanto, a perda de massa da amostra de controle possui valor aproximado ao deste tratamento, 7,50\% (Figura 1). Estes resultados diferem dos resultados esperados com a aplicação da cera de abelha, que por ser hidrofóbica, atribuiria melhor propriedade de barreira à umidade de água às coberturas, dificultando a perda de massa. 
Comparando estes dados com os obtidos nos testes pode-se presumir que a cera de abelha não atuou como barreira à umidade conforme esperado, mesmo estando presente na formulação das matrizes filmogênicas e que, portanto, o método utilizando a lecitina de soja como emulsificante não foi eficiente, possivelmente devido à grande higroscopicidade desse surfactante.

\subsection{Cor dos Tomates}

A Figura 2 mostra as variações do parâmetro L, que varia de 0 para preto a 100 para branco. Para todos tratamentos houve decréscimo no valor de L, o escurecimento do fruto provocado pelo processo de maturação. No entanto, observa-se que a cobertura provocou menores reduções em seus valores quando comparados com o grupo controle, principalmente nos tratamentos T7 e T8. Nestes casos a cobertura reteve luminosidade e garantiu maior brilho quando comparado com os demais tratamentos e o grupo de controle.

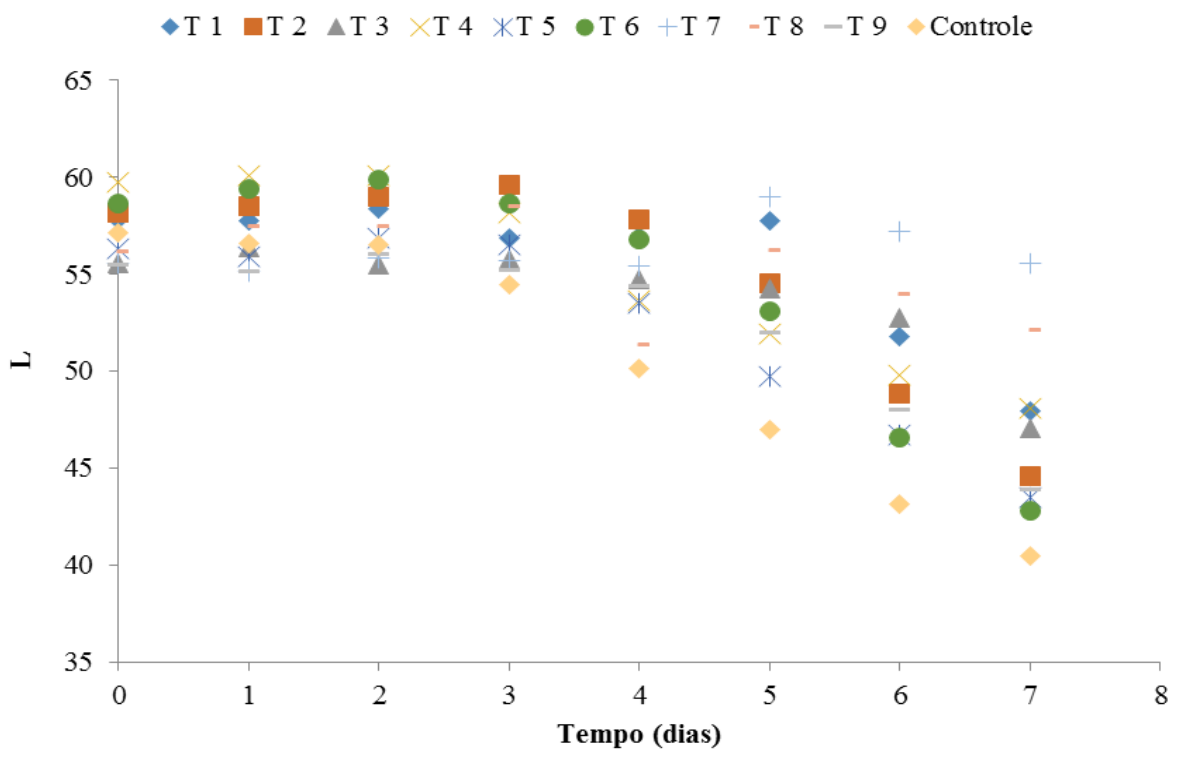

Figura 2 - Variações do parâmetro L para os tomates revestidos com as diferentes coberturas.

O parâmetro $a^{*}$, que varia do negativo para verde e positivo para vermelho, também obteve sua menor variação nos frutos dos tratamentos T7 e T8. De acordo com o gráfico da Figura 3 é possível perceber que T7 e T8 apresentam os menores valores de $\mathrm{a}^{*}$, se distanciando do vermelho, mais próximos à região espacial do verde. Portanto, a partir destes dados pode-se dizer que para estes tratamentos a cobertura foi eficiente em retardar o amadurecimento dos tomates. $\mathrm{O}$ parâmetro $\mathrm{b}^{*}$, que varia do negativo para azul e positivo para amarelo, apresentou aumento nos seus valores até o quinto dia e a partir deste decresceu, sempre mais próximos à região do amarelo (Figura 4). 


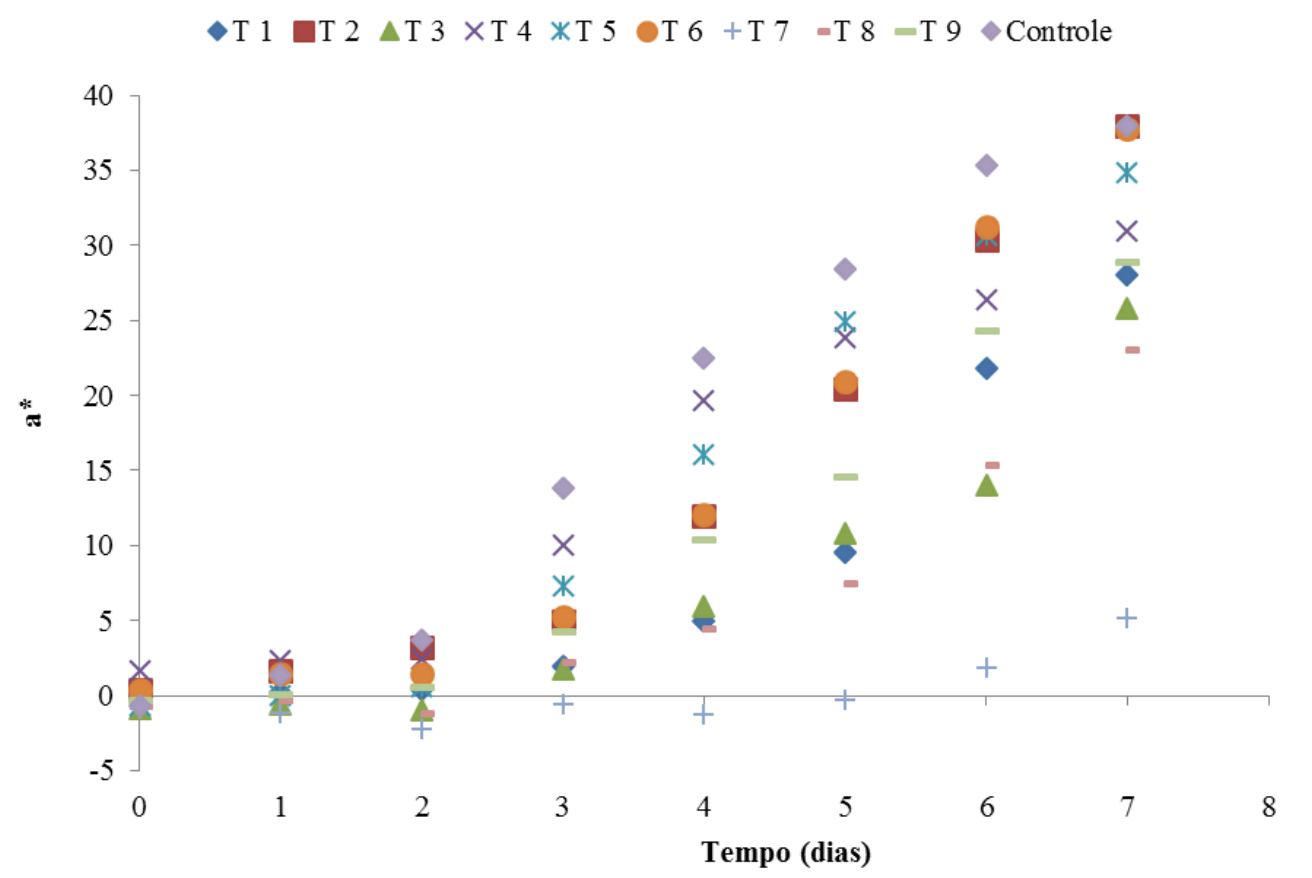

Figura 3 - Variações do parâmetro a* para os tomates revestidos com as diferentes coberturas.

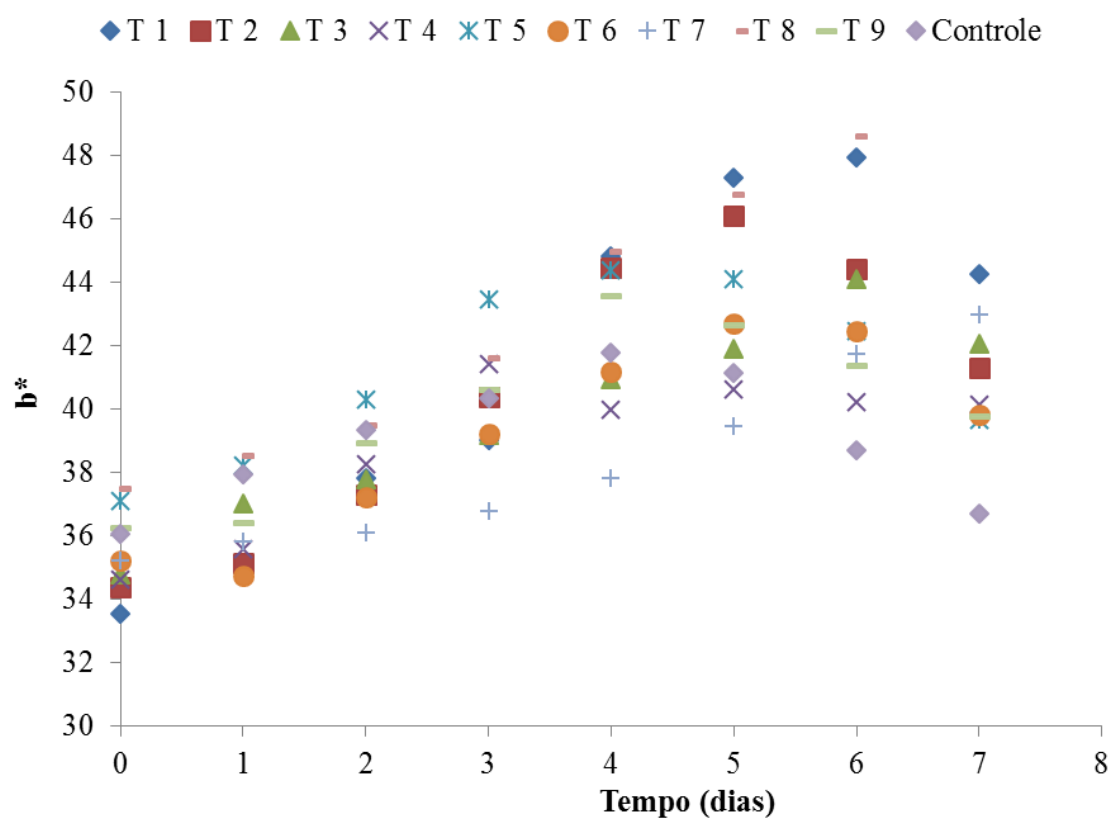

Figura 4 - Variações do parâmetro b* para os tomates revestidos com as diferentes coberturas.

Costa et al. (2012) obtiveram resultados semelhantes para os parâmetros L e a* na utilização de revestimentos à base de quitosana $(1 \%)$ e argila $(1 \%)$ em tomates sob refrigeração. No entanto, o comportamento do parâmetro $b^{*}$ avaliado pelos autores diferem do obtido no presente trabalho, uma vez que este parâmetro decresceu em função do tempo de armazenamento. 


\section{9 a 22 de outubro de 2014 \\ Florianópolis/SC}

Oliveira et al. (2012) também observaram reduções na luminosidade (L) de tomates revestidos com pectina em concentrações de $2 \%, 5 \%$ e $8 \%$, sendo que para a última concentração este aumento se deu apenas até o segundo dia, quando essa constante aumentou significativamente alcançando valores maiores que o do ponto inicial. Estes mesmos autores observaram aumento nos valores de intensidade de vermelho até o sétimo dia para o grupo de controle e revestimento a 5\%, os demais revestimentos apresentaram reduções nos valores de $a^{*}$ a partir do quarto dia. A utilização da pectina também possibilitou aumento gradual da coloração amarela nos revestimentos a $5 \%$ e $8 \%$ e reduções nos grupos de controle e concentração de $2 \%$.

\section{CONCLUSÃO}

As coberturas à base de fécula de mandioca, cera de abelha, lecitina de soja e glicerol não foram eficientes como barreira à umidade provocando maior perda de massa nos frutos que os observados no grupo controle, provavelmente devido à alta higroscopicidade da lecitina de soja. Porém, as coberturas estudadas foram capazes de alterar o processo de amadurecimento do tomate. A mistura filmogênicas composta de $3 \%$ de fécula de mandioca, $2 \%$ de cera de abelha, $0,3 \%$ de glicerol e $2 \%$ de lecitina de soja foi a que apresentou os melhores resultados no retardamento do amadurecimento de tomates, com retenção de luminosidade e maior brilho, além da fixação da cor verde.

\section{REFERÊNCIAS}

BATISTA, P. F.; SANTOS, A. E. O.; PIRES, M. M. ML.; DANTAS, B. F.; PEIXOTO, A. R.; ARAGÃO, C. A. Utilização de filmes plásticos e comestíveis na conservação pós-colheita de melão amarelo. Hortic. Bras., v. 25, p. 572-576, 2007.

COSTA, T. L. E; OLIVEIRA, T. A.; SANTOS, F. K. G.; AROUCHA, E. M. M.; LEITE, R. H. L. Avaliação de coberturas comestíveis compostas por quitosana e argila no revestimento de tomates sob refrigeração pelo método dipping. Revista Verde. v. 7, p. 12-19, 2012.

DAMASCENO, S.; OLIVEIRA, P. V. S.; MORO, E.; MACEDO JR, E. K.; LOPES, M. C.; VICENTINI, N. M. Efeito da aplicação de película de fécula de mandioca na conservação póscolheita de tomate. Ciênc. Tecnol. Aliment., v. 23, p. 377-380, 2003.

EMBRAPA. Embrapa Mandioca e Agricultura. Circular Técnica 98: Biofilme comestível biodegradável de amido de mandioca e refrigeração reduzem dano larval de mosca-das-frutas. Cruz das Almas, 2010.

FAKHOURI, F. M.; FONTES, L. C. B.; GONÇALVES, P. V. M.; MILANEZ, C. R.; STEEL, C. J.; COLLARES-QUEIROZ, F. P. Filmes e coberturas comestíveis compostas à base de amidos nativos e gelatina na conservação e aceitação sensorial de uvas Crimson. Ciênc. Tecnol. Aliment, v. 27, p. 369-374, 2007. 
FAO. FAOSTAT. Disponível em <http://faostat.fao.org/site/339/default.aspx>. Acesso em: 24 junho 2014.

LAROTONDA, F. D. S. Desenvolvimento de Biofilmes a partir de Fécula de Mandioca. 2002. 77f. Dissertação (Mestrado em Engenharia de Alimentos) - Centro Tecnológico, Universidade Federal de Santa Catarina, Florianópolis, SC.

OLIVEIRA, E. N. A.; MARTINSH, J. N.; SANTOS, D. C.; GOMES, J. P.; ALMEIDA, F. A. C. Armazenamento de tomates revestidos com pectina: avaliação colorimétrica. Rev. Caatinga. v. 25, n.4, p. 19-25, 2012.

OLIVEIRA, M. A.; CEREDA, M. P. Pós-Colheita de pêssegos (Prunus pérsica L. Bastsch) revestidos com filmes a base de amido como alternativa à cera comercial. Ciênc. Tecnol. Aliment. v. 23 , p. $28-33,2003$.

QUINTANA, A. C. Agrianual 2013: Anuário da Agricultura Brasileira. São Paulo: Editora FNP, 2013.

RIGO, L. N. Desenvolvimento e Caracterização de Filmes Comestíveis. 2006. 130 f. Dissertação (Mestrado em Engenharia de Alimentos) - Departamento de Ciências Agrárias, Universidade Regional Integrada do Alto Uruguai e das Missões, Campus de Erechim, RS.

ROJAS-GRAÜ, M. A.; SOLIVA-FORTUNY, R.; MARTÍN-BELLOSO, O. Edible coatings to incorporate active ingredients to fresh-cut fruits: a review. J. Trends of Food Sci. and Technol. v. 20, p. 438, 2009. 